Educ. Sci. 2013, 3, 1-16; doi:10.3390/educsci3010001

\title{
sciences
}

ISSN 2227-7102

www.mdpi.com/journal/education

Article

\section{Ten Years' Experience with an E-Learning Lecture Series on Cancer Biology and Pharmacology}

\section{Thomas Efferth}

Department of Pharmaceutical Biology, Institute of Pharmaceutical Biology, University of Mainz, Staudinger Weg 5, 55128 Mainz, Germany; E-Mail: efferth@uni-mainz.de; Tel.: +49-6131-3925751; Fax: +49-6131-3923752

Received: 10 October 2012; in revised form: 8 December 2012 / Accepted: 8 January 2013 / Published: 14 January 2013

\begin{abstract}
In life sciences, the internet is an indispensable medium for research, but has not yet realized its full potential for teaching. The concept of e-learning has been developed over the past decades for undergraduate, graduate and postgraduate programs. We set up an e-learning lecture on cancer biology and pharmacology that was first offered in 2003 to students of Molecular Biotechnology at the University of Heidelberg and to students of Pharmacy at the University of Mainz, Germany. The present paper recapitulates the first decade of experiences with this e-learning lecture from both the students' and the teachers' perspectives. A total of 317 students during the past 10 years participated in a survey. In general, the students enjoyed the possibilities that self-controlled learning offers. E-learning interested them as a novel educational method. They felt quite comfortable listening to the material despite the interdisciplinary nature of the lectures, which included molecular biological, pharmacological and medical aspects of cancer biology and pharmacology. This lecture was the first e-learning experience for the majority of students, and their impressions were generally positive. The students not only indicated that they would like to continue with e-learning, but also would recommend e-learning to other students. Remarkably, the majority of students would like to see more e-learning offered in their present curricula. They indicated interest in mixed forms of traditional learning and e-learning ("blended learning"), although it is recognized that face-to-face contact between teachers and students is critical. Overall, many students would consider e-learning for further and continuing education after graduation.
\end{abstract}


Keywords: cancer biology; constructivism; didactics e-learning; medicine; molecular biology; pharmacology

\section{Introduction}

In life sciences, the internet is an indispensable medium for research and its potential for teaching has realized. The concept of e-learning has been developed over the past decades not only for postgraduate programs and distance learning, but also for undergraduate and graduate programs at universities [1-7].

Although applications of e-learning are numerous and it can provide up-to-date teaching at a high academic level, the development of e-learning in pharmacology and pharmacy is still in its infancy [8]. For this reason, we set up an e-learning lecture series on cancer biology and pharmacology. This e-learning lecture was first offered in 2003 to students of Molecular Biotechnology at the University of Heidelberg and to students of Pharmacy at the University of Mainz, Germany. The present paper recapitulates our first decade of experience with this e-learning series from both the students' and the teachers' perspectives. Results from 2003 to 2012 were evaluated here.

The e-learning lecture series was a central part of several efforts to foster self-directed learning in our Pharmacy program. Although many pharmacy students are interested in cancer biology, it is not currently included in the standard Pharmacy curriculum. Therefore, this e-learning lecture on cancer biology and pharmacology was implemented as an optional offering, which was accepted by $10 \%-20 \%$ of students. The students who opted to participate were provided with 12 lessons to download over the course of the semester.

The students were required to answer and submit two questionnaires by the end-of-semester break to obtain a certificate of attendance, which contained neither marks nor scores. One questionnaire contained scientific questions relating to the specific contents of the lecture. The intention was not to conduct a written examination, but rather to ensure to some extent that the students really listened to the e-learning lectures. The students were also allowed to form learning groups and to answer the questions collectively. A second questionnaire contained questions about learning and e-learning. The analysis of this questionnaire is subject of the present paper.

Some students were interested in receiving a certificate with a grade. These students were allowed to write an essay of 2500-3000 words on a topic related to the e-learning lectures in order to earn a grade. We provided basic literature to the students and they searched for additional literature on their topic of choice to elaborate on in their essay.

As an additional offer for the most motivated students, we performed a "Drug Club" seminar, in which the students presented their written essays as oral presentations to all Pharmacy students, even those who did not participate in the e-learning program. This "Drug Club" seminar served to promote the e-learning lecture to all Pharmacy students.

The aim of the present paper is to evaluate the students' responses to the questionnaire about learning and e-learning in order to gain insight into the students' needs and interests. The results of this 
questionnaire may serve as a basis for improving the existing e-learning program and establishing further e-learning programs in Pharmacy and related fields of life science.

\section{Methods Section}

Technical implementation of the e-learning lecture was performed by Georg Seppmann (Virtueller Campus, Rheinland-Pfalz, Mainz, Germany) by means of Microsoft Producer, as previously described [9]. The lecture was recorded using a commercial camcorder. Microsoft Producer was used to coordinate and synchronize the PowerPoint slides and the video track. Selected screenshots of the lectures are shown in Figure 1.

Figure 1. Screenshots from the e-learning lecture series [9].

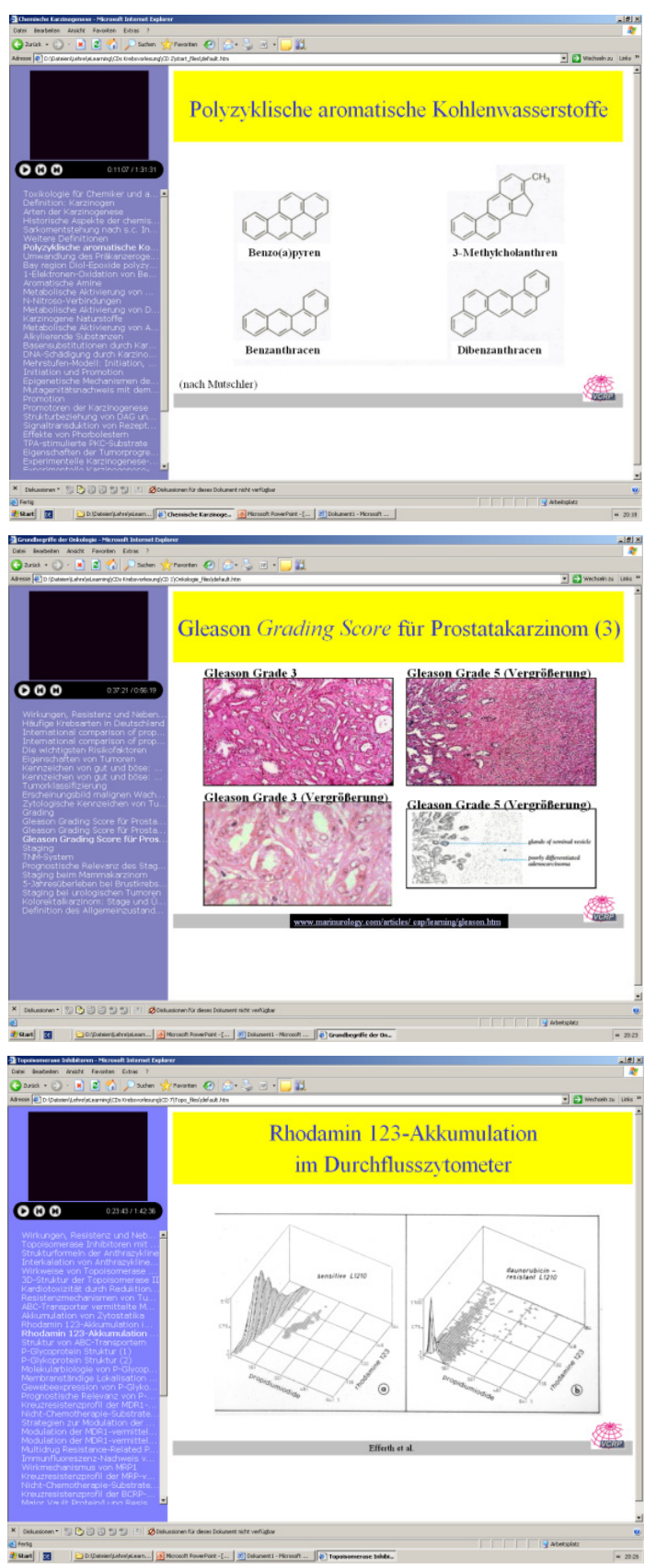


Figure 1. Cont.

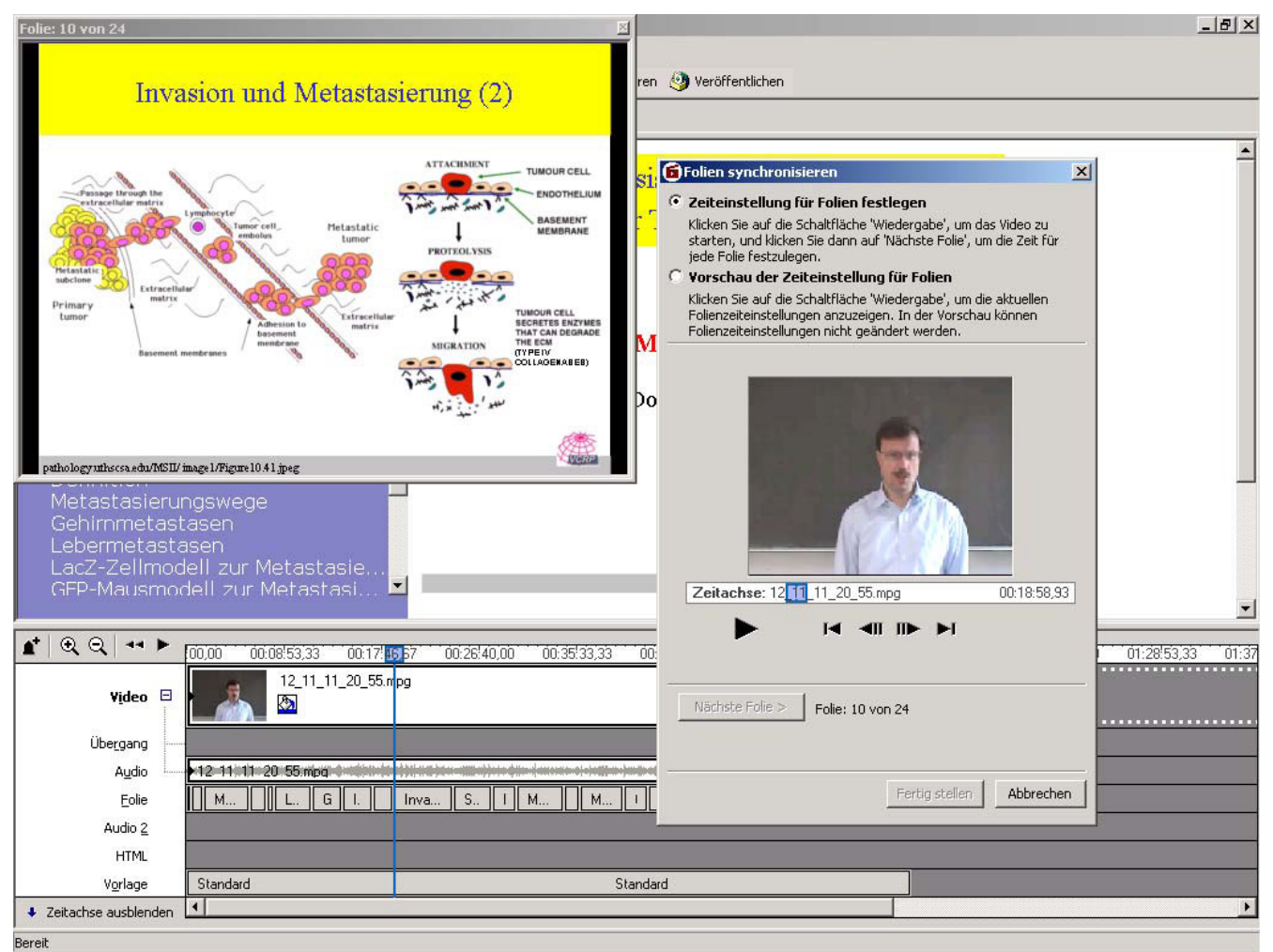

Microsoft Producer is an open-access software for the production of PowerPoint-based video presentations that can then be burned onto a $\mathrm{CD}$ or uploaded onto the internet or local area network (LAN). Microsoft Producer requires Windows Media Server [10,11] (LiNUX and Macintosh operating systems cannot be used).

The e-learning lecture series was organized as 12 independent lessons consisting of 5 lectures in cancer biology and seven lectures in cancer pharmacology. The topics were

1. Basics in oncology

2. Chemical carcinogenesis

3. Proliferation

4. Metastasis

5. Apoptosis

6. Principles of chemotherapy

7. DNA topoisomerase inhibitors

8. Antimitotic drugs

9. Platin compounds

10. Alkylating agents

11. Antimetabolites

12. Hormones and antihormones 


\section{Results and Discussion}

The entire number of students, which have been offered e-learning, was 2680 during the past 10 years. Of them, $725(=27.05 \%)$ downloaded the e-learning lecture series and 317 students filled and submitted the questionnaires $(11.83 \%)$ (Table 1$)$.

The questionnaire was divided into five major sets of questions. The aim of the questionnaire was to gain insight into student access to computers and university computing infrastructure as well as students' computer skills and interest in e-learning. Although students came from two different programs (Molecular Biotechnology and Pharmacy) and two different universities (University of Heidelberg and University of Mainz), there were no differences in the trends of answers given by the two groups of students. Therefore, all answers were evaluated in one analysis. During the past 10 years, a total of 317 students participated in the questionnaire. The results are shown in Tables 2-6.

Inquiring about the students' access to computers at the university and at home clearly showed that the students are faced with rather satisfactory technical conditions (Table 2). In addition, students are aware of the importance of computer skills for their professional careers and they are willing to use computers and the internet for learning, indicating that the preconditions for e-learning offers are satisfactory.

The next set of questions focused on the students' personal learning style in order to find out whether the students were open-minded to experiencing e-learning and adequately prepared. The answers are summarized in Table 3. The students said that e-learning was suitable to their personal learning style (question 2.1), although these e-learning lectures were the first that the vast majority of students had ever attended (question 3.1). This indicates that e-learning not only sparked their interest as a novel educational method, but also that they felt quite comfortable listening to this e-learning lecture.

A number of questions led to rather indifferent trends, i.e., whether learning is influenced more by external influences such as examination deadlines or internal factors such as intrinsic motivation (questions 2.21, 2.19, 2.23). Interestingly, the students preferred self-controlled learning (question 2.6, 2.10 to 2.14 ), but the learning contents and goals were (of course) externally defined by the program curriculum (questions $2.7,2.9,2.20$ ).

It was also interesting that students reported that they liked having the freedom to choose when and where they learn. This indicates that the time- and location-independent aspect of e-learning suits students' preferences. In line with this attitude is the assertion that students prefer to define their personal learning goals (question 2.35). 
Table 1. Participation of students during the past 10 years on the e-learning lecture series.

\begin{tabular}{|c|c|c|c|c|c|c|}
\hline Year & $\begin{array}{c}\text { Total number } \\
\text { of students }\end{array}$ & $\begin{array}{c}\text { E-learning } \\
\text { participants }\end{array}$ & $\begin{array}{l}\text { Number of filled } \\
\text { questionnaires }\end{array}$ & $\begin{array}{l}\text { Percentage }(\%, \text { total } \\
\text { number of students/ } \\
\text { e-learning participants) }\end{array}$ & $\begin{array}{c}\text { Percentage }(\%, \text { total } \\
\text { number of students/number } \\
\text { of filled questionnaires })\end{array}$ & \\
\hline summer semester 2003 & 220 & 52 & 20 & 23.64 & 9.09 & \\
\hline winter semester 2003 & 180 & 49 & 33 & 27.22 & 18.33 & \\
\hline summer semester 2004 & 220 & 96 & 50 & 43.64 & 22.73 & \\
\hline winter semester 2004 & 180 & 56 & 37 & 31.11 & 20.56 & \\
\hline summer semester 2005 & 180 & 46 & 15 & 25.56 & 8.33 & \\
\hline winter semester 2005 & 220 & 41 & 23 & 18.64 & 10.45 & \\
\hline summer semester 2006 & 180 & 47 & 18 & 26.11 & 10.00 & \\
\hline winter semester 2006 & 180 & 28 & 16 & 5.56 & 8.89 & \\
\hline summer semester 2007 & 180 & 35 & 9 & 19.44 & 5 & \\
\hline winter semester 2007 & 180 & 42 & 3 & 23.33 & 1.67 & \\
\hline summer semester 2008 & 180 & 54 & 30 & 30.00 & 16.67 & \\
\hline winter semester 2008 & 180 & 68 & 22 & 37.78 & 12.22 & \\
\hline summer semester 2009 & 50 & 20 & 11 & 40.00 & 22.00 & \\
\hline winter semester 2009 & 50 & 19 & 1 & 38.00 & 2.00 & \\
\hline summer semester 2010 & 50 & 33 & 2 & 66.00 & 4.00 & \\
\hline winter semester 2010 & 50 & 11 & 7 & 22.00 & 14.00 & \\
\hline summer semester 2011 & 50 & 10 & 5 & 20.00 & 10.00 & \\
\hline winter semester 2011 & 50 & 8 & 1 & 16.00 & 2.00 & \\
\hline summer semester 2012 & 50 & 8 & 11 & 16.00 & 22.00 & \\
\hline winter semester 2012 & 50 & 2 & 3 & 4.00 & 6.00 & \\
\hline $\operatorname{sum}(n)$ & 2680 & 725 & 317 & & & \\
\hline \multicolumn{6}{|c|}{$\%$ e-learning participants related to total number of students } & $27.05 \%$ \\
\hline \multicolumn{6}{|c|}{$\%$ number of filled questionnaires related to total number of students } & $11.83 \%$ \\
\hline \multicolumn{6}{|c|}{$\%$ number of filled questionnaires related to e-learning participants } & $43.72 \%$ \\
\hline
\end{tabular}


Table 2. General questions on computer facilities of students.

\begin{tabular}{|c|c|c|c|c|c|}
\hline \multirow{2}{*}{ No. } & \multirow{2}{*}{ Question } & \multicolumn{4}{|c|}{ Response (\%) } \\
\hline & & \multicolumn{2}{|c|}{ yes } & \multicolumn{2}{|c|}{ no } \\
\hline 1.1. & Do you have access to the internet? & \multicolumn{2}{|c|}{99.06} & \multicolumn{2}{|c|}{0.94} \\
\hline 1.2. & Is knowledge obtained from the internet important for your professional career? & \multicolumn{2}{|c|}{85.62} & \multicolumn{2}{|c|}{14.38} \\
\hline 1.3. & Is knowledge about the internet important for your professional career? & \multicolumn{2}{|c|}{75.40} & \multicolumn{2}{|c|}{24.60} \\
\hline 1.4. & Is your internet connection at home adequate? & \multicolumn{2}{|c|}{83.00} & \multicolumn{2}{|c|}{17.00} \\
\hline 1.5 . & Is the number of computers for students' use at your university sufficient? & \multicolumn{2}{|c|}{52.61} & \multicolumn{2}{|c|}{47.39} \\
\hline 1.6. & Are the computer rooms for students at your university satisfying? & \multicolumn{2}{|c|}{74.43} & \multicolumn{2}{|c|}{25.57} \\
\hline 1.7. & Are the computer room hours rooms sufficiently long? & \multicolumn{2}{|c|}{85.34} & \multicolumn{2}{|c|}{14.66} \\
\hline \multirow[t]{2}{*}{1.8.} & Are the computer room equipment and printers sufficient? & \multicolumn{2}{|c|}{44.00} & \multicolumn{2}{|c|}{56.00} \\
\hline & & yes & mostly yes & mostly no & no \\
\hline 1.9. & Are you generally satisfied with the internet loading times of the university computers? & 15.51 & 49.17 & 28.38 & 6.93 \\
\hline 1.10 . & Are you generally satisfied with the IT-support at your university? & 19.08 & 71.20 & 9.38 & 0.32 \\
\hline
\end{tabular}


Table 3. Questions on the personal learning style of students.

\begin{tabular}{|c|c|c|c|c|c|}
\hline \multirow{2}{*}{ No. } & \multirow{2}{*}{ Question } & \multicolumn{4}{|c|}{ Response (\%) } \\
\hline & & always & often & seldom & never \\
\hline 2.1. & How much does e-learning agree with your personal learning style? & 46.00 & 43.14 & 10.54 & 0.32 \\
\hline 2.2 . & My motivation to learn is determined by extrinsic influences. & 6.05 & 72.61 & 21.34 & 0 \\
\hline 2.3 . & My motivation to learn is determined by my intrinsic desire. & 19.3 & 71.52 & 9.18 & 0 \\
\hline 2.4 . & If I like to learn on a voluntary basis, I attend classes at the university. & 5.99 & 55.52 & 36.91 & 1.58 \\
\hline 2.5 . & If I like to learn on a voluntary basis, I ask experts. & 1.60 & 22.44 & 60.58 & 15.38 \\
\hline 2.6 . & If I like to learn on a voluntary basis, I try to learn material by myself. & 24.29 & 69.72 & 1.89 & 0 \\
\hline 2.7. & My learning topics are determined by others. & 5.79 & 82.32 & 10.93 & 0.96 \\
\hline 2.8. & My learning topics are determined by myself. & 3.17 & 54.60 & 41.90 & 0.32 \\
\hline 2.9 . & I like to be guided by learning goals defined by others. & 4.52 & 63.23 & 30.97 & 1.29 \\
\hline 2.10 . & I define my own intensity of learning regarding how much I want to know. & 28.66 & 59.55 & 11.46 & 0.32 \\
\hline 2.11. & I define my own intensity of learning regarding how much I want to understand. & 41.64 & 51.74 & 6.62 & 0 \\
\hline 2.12. & I define my own intensity of learning regarding how much I want to apply myself. & 24.92 & 53.99 & 21.09 & 0 \\
\hline 2.13. & I try to learn the main content by heart. & 53.97 & 38.66 & 7.67 & 0 \\
\hline 2.14. & I try to understand the main content. & 67.51 & 31.86 & 0.63 & 0 \\
\hline 2.15. & I prefer to learn alone. & 13.56 & 65.93 & 20.50 & 0 \\
\hline 2.16. & For optimal learning, I need learning devices. & 10.82 & 48.85 & 39.34 & 0.98 \\
\hline 2.17. & For optimal learning, I need feedback. & 11.32 & 39.31 & $44 ., 65$ & 4.72 \\
\hline 2.18. & I need guidance by a teacher. & 4.43 & 27.53 & 60.13 & 7.91 \\
\hline 2.19. & For optimal learning, I need deadlines. & 22.78 & 48.73 & 22.47 & 6.01 \\
\hline 2.20 . & For optimal learning, I need pre-structured learning content. & 14.87 & 43.67 & 33.23 & 8.23 \\
\hline 2.21. & I need precise planning regarding the starting time and duration of learning. & 14.56 & 39.16 & 35.92 & 10.36 \\
\hline 2.22 . & I decide by myself, at which location I learn. & 71.75 & 26.35 & 1.90 & 0 \\
\hline 2.23 . & I learn only for examinations. & 4.93 & 65.46 & 26.32 & 3.29 \\
\hline 2.24 . & I learn continuously. & 7.59 & 37.03 & 53.80 & 1.58 \\
\hline 2.25. & I plan repeating learning phases in regular intervals. & 7.28 & 31.33 & 52.22 & 9.18 \\
\hline
\end{tabular}


Table 3. Cont.

\begin{tabular}{|c|c|c|c|c|c|}
\hline \multirow{2}{*}{ No. } & \multirow{2}{*}{ Question } & \multicolumn{4}{|c|}{ Response (\%) } \\
\hline & & always & often & seldom & never \\
\hline 2.26 . & I prepare written excerpts of learning content. & 57.41 & 30.60 & 10.73 & 1.26 \\
\hline 2.27 . & I regularly work with my written records. & 9.49 & 41.46 & 45.25 & 3.80 \\
\hline 2.28 . & I prepare learning maps. & 9.68 & 27.42 & 29.68 & 33.23 \\
\hline 2.29 . & Theoretical content is easy to learn. & 10.73 & 62.46 & 25.24 & 1.58 \\
\hline 2.30 . & Practical content is easy to learn. & 28.06 & 63.41 & 8.20 & 0.32 \\
\hline 2.31 . & I prefer connections between theoretical and practical content. & 34.08 & 57.56 & 8.36 & 0 \\
\hline 2.32 . & I need concrete illustration for optimal learning. & 11.82 & 51.76 & 35.78 & 0.64 \\
\hline 2.33 . & I need practical exercises to try out. & 12.10 & 51.91 & 34.71 & 1.27 \\
\hline 2.34 . & I have reserved learning times in my schedule. & 16.14 & 43.04 & 34.18 & 6.65 \\
\hline 2.35 . & I define personal learning goals. & 34.92 & 53.02 & 12.38 & 0 \\
\hline 2.36 . & I reward myself after finishing my lesson. & 25.40 & 38.73 & 30.79 & 5.08 \\
\hline 2.37 . & I try to specifically apply learned content. & 9.78 & 53 & 36.91 & 0.31 \\
\hline 2.38 . & I imagine application possibilities. & 9.57 & 53.80 & 35.31 & 1.32 \\
\hline 2.39 . & I critically scrutinize learning content. & 15.70 & 48.72 & 32.05 & 3.53 \\
\hline
\end{tabular}

Table 4. Comparison of e-learning and traditional learning in the opinion of students.

\begin{tabular}{|c|c|c|c|}
\hline \multirow{2}{*}{ No. } & \multirow{2}{*}{ Question } & \multicolumn{2}{|c|}{ Response (\%) } \\
\hline & & yes & no \\
\hline 3.1. & Have you used e-learning before? & 10.13 & 90.51 \\
\hline 3.2. & Do you know of other e-learning offers at your university? & 10.16 & 89.84 \\
\hline 3.3. & Do you know of other e-learning offers available to you? & 7.01 & 92.99 \\
\hline 3.4. & Do you miss e-learning offers at your university or one that are otherwise available to you? & 70.38 & 28.66 \\
\hline 3.5 . & Does e-learning play a role in the politics of your university? & 12.72 & 87.28 \\
\hline 3.6. & If yes, is e-learning covered in official teaching evaluation questionnaires? & 4.31 & 95.69 \\
\hline
\end{tabular}


Table 5. Questions on the present e-learning lecture on cancer biology and pharmacology.

\begin{tabular}{|c|c|c|c|c|c|}
\hline \multirow{2}{*}{ No. } & \multirow{2}{*}{ Question } & \multicolumn{4}{|c|}{ Response (\%) } \\
\hline & & \multicolumn{2}{|c|}{ yes } & \multicolumn{2}{|c|}{ no } \\
\hline \multirow[t]{2}{*}{4.1.} & Did you face problems understanding the contents? & \multicolumn{2}{|c|}{5.16} & \multicolumn{2}{|c|}{94.84} \\
\hline & & \multicolumn{2}{|c|}{ exactly right } & \multicolumn{2}{|c|}{ too biased } \\
\hline \multirow[t]{2}{*}{4.2 . } & $\begin{array}{l}\text { Was the focus too much on medicine, on molecular biology, on pharmacy or } \\
\text { was the interdisciplinary mix exactly what you liked most? }\end{array}$ & \multicolumn{2}{|c|}{97.47} & \multicolumn{2}{|c|}{2.53} \\
\hline & & always & often & seldom & never \\
\hline 4.3. & Was the program download too slow? & 0 & 2.60 & 44.01 & 53.40 \\
\hline 4.4 . & Did you have frequent program interruptions? & 0 & 2.91 & 19.74 & 67.64 \\
\hline 4.5 . & Did you have problems downloading the files? & 0 & 2.21 & 16.61 & 81.19 \\
\hline \multirow[t]{2}{*}{ 4.6. } & Did you have other problems? & 7.43 & 8.55 & 12.27 & 71.75 \\
\hline & & excellent & good & fair & bad \\
\hline 4.7. & How was the presentation of the e-learning lecture regarding content? & 35.44 & 63.61 & 0.95 & 0 \\
\hline 4.8. & How was the presentation of the e-learning lecture regarding didactics? & 28.16 & 67.41 & 4.43 & 0 \\
\hline 4.9. & Was the content easy to understand? & 37.66 & 58.86 & 3.48 & 0 \\
\hline 4.10 . & Was the content up-to-date? & 40.06 & 57.05 & 2.88 & 0 \\
\hline 4.11 . & Was the content exciting? & 28.71 & 56.45 & 14.84 & 0 \\
\hline 4.12 . & How was the design of the screen? & 20.83 & 58.65 & 20.51 & 0 \\
\hline \multirow[t]{2}{*}{4.13.} & The presentation by the teacher was... & 25.95 & 68.04 & 5.70 & 0.32 \\
\hline & & lots of & many & few & none \\
\hline 4.14. & Are there other courses with similar contents at your university? & 0 & 0.04 & 64.89 & 30.85 \\
\hline
\end{tabular}


Table 6. Conclusions and perspectives of the students.

\begin{tabular}{|c|c|c|c|c|c|}
\hline \multirow{2}{*}{ No. } & \multirow{2}{*}{ Question } & \multicolumn{4}{|c|}{ Response (\%) } \\
\hline & & very good & good & satisfying & not satisfying \\
\hline \multirow[t]{2}{*}{5.1.} & How would you score this e-learning lecture? & 32.49 & 61.83 & 5.05 & 0.63 \\
\hline & & absolutely & perhaps & rather not & no \\
\hline 5.2. & Would you recommend this e-learning lecture to other students? & 76.66 & 23.03 & 0.32 & 0 \\
\hline 5.3 . & Would you use e-learning again? & 70.06 & 28.66 & 1.27 & 0 \\
\hline 5.4. & Did you take advantage of this e-learning lecture for examinations relevant to your curriculum? & 32.15 & 32.15 & 23.47 & 12.22 \\
\hline 5.5 . & Did you take advantage of this e-learning lecture for your professional development? & 35.02 & 46.46 & 18.52 & 0 \\
\hline 5.6. & Did you take advantage of this e-learning lecture for the general gain of knowledge? & 76.38 & 18.77 & 4.85 & 0 \\
\hline 5.7. & Do you regard e-learning in general as attractive and future-directed? & 54.61 & 38.49 & 6.91 & 0 \\
\hline 5.8. & Do you think that e-learning should be implemented in existing programs ("blended learning")? & 46.60 & 36.89 & 16.50 & 1.62 \\
\hline 5.9. & The existing traditional programs should be run without e-learning & 5.18 & 16.5 & 38.83 & 39.48 \\
\hline 5.10 & E-learning-based distance learning is attractive for specific target groups and persons & 63.61 & 31.96 & 4.43 & 0 \\
\hline 5.11. & E-learning-based distance learning programs should also contain face-to-face teaching & 42.41 & 40.19 & 13.29 & 4.11 \\
\hline 5.12 . & $\begin{array}{l}\text { Would you use e-learning for further and continuing education after completion of your } \\
\text { undergraduate and graduate programs? }\end{array}$ & 70.03 & 23.34 & 4.42 & 2.21 \\
\hline 5.13. & $\begin{array}{l}\text { Are you willing to pay for e-learning offers during your later professional further and } \\
\text { continuing education? }\end{array}$ & 24.44 & 47.30 & 21.27 & 6.98 \\
\hline
\end{tabular}


Next, we asked a series of questions about e-learning in general (Table 4). As was expected, the students were largely unaware of other e-learning offers at their university or within their specific program (questions 3.2 to 3.6). This data agrees with the general trend of a rather reluctant introduction of e-learning as yet.

Although many universities worldwide have spent considerable effort to establish e-learning programs, it seems that students are frequently unaware that such programs exist at their home universities and at other universities abroad. Indeed, several authors have reported on academic e-learning in pharmacy and pharmacology. For instance, the ETH Zürich and the University of Basel, Switzerland implemented an e-learning-based curriculum for Pharmaceutical Sciences [12]. Clinical pharmacology at the Leiden University Medical Centre is primarily taught by the Teaching Resource Centre's (TRC) Pharmacology database [13]. Nearly every course has a chapter in the TRC database for self-study. The authors demonstrated that students with lower exam scores derived an especially great benefit from using the database. The positive overall outcomes of e-learning, as reported by these authors and corroborated by our present study, should encourage teachers and students alike to better utilize e-learning in the future.

The students' opinions of the e-learning lecture series on tumor biology and pharmacology are summarized in Table 5. The contents were not overly complex, and the students liked the interdisciplinary mixture of molecular biology, pharmacology and medicine presented (questions 4.1 and 4.2). Technical problems with computers and software were not an issue (questions 4.3 to 4.6). The students also liked the preparation and presentation of the e-learning lecture with regards to content and didactics (questions 4.7 to 4.13 ).

To draw conclusions and develop perspectives for the future, the students were asked for their general opinion of e-learning after having completed the e-learning lecture series (Table 6). It was pleasing that the impressions were generally positive. Not only would the students continue with further e-learning based lectures, but they would also recommend e-learning to other students (questions 5.2 and 5.3). They appreciated the educational value and the possible professional benefits of the e-learning program (questions 5.4 to 5.6). It is remarkable that the majority of students would like to have more e-learning offers in their present curricula, particularly in the form of mixed traditional learning and e-learning ("blended learning") (questions 5.8 and 5.9). They were open to using e-learning for distance learning, although they agreed that face-to-face contact with teachers and students (phases of presence) should be implemented (questions 5.10 and 5.11). As a consequence, many students would be willing to take advantage of e-learning for further education after completing their present undergraduate and graduate programs (questions 5.12 and 5.13).

E-learning plays a critical role in postgraduate and life-long learning. In addition, in the field of pharmacy and pharmacology, several publications on the use of e-learning for postgraduates at universities [14-16] as well as at other educational institutions [17,18] have demonstrated that e-learning may gain increased importance in this sector in the future. The results of this investigation show that students are aware that e-learning offers potential for life-long learning and that they are willing to use e-learning after graduation for further professional development.

The development of e-learning was mainly driven by professionals from humanities (e.g., pedagogy, sociology) on the one hand and from information sciences (e.g., informatics, media design) on the other. Scientists of natural and life sciences (biology, chemistry, physics, medicine, pharmacy 
and related fields) have generally been more interested in the application of e-learning than in basic research on the method. In the present paper, we describe our experience with an e-learning-based interdisciplinary lecture series that covered topics in life science. Although selected content regarding cancer biology and pharmacology is included in the teaching of molecular biology, human medicine, pharmacology and pharmacy, the topic of cancer is not comprehensively covered in the curricula of these disciplines in Germany. For this reason, and because of the relevance of this topic, we decided to set up an e-learning program as an extracurricular offer for motivated students. The e-learning lecture was offered to students of Molecular Biotechnology (Institute of Pharmacy and Molecular Biotechnology, University of Heidelberg, Germany) and Pharmacy (Institute of Pharmacy and Biochemistry, University of Mainz, Germany). As outlined above, the reactions of the students were favorable both towards e-learning in general and toward the present lecture series in specific.

Despite the generally positive reactions of the students, it should be kept in mind that the lecture was not an integral part of the curricula and that only a subset of students elected to participate in this e-learning program. Therefore, their opinion might not reflect the opinion of all students. We may have selected the most capable students, those who have enough leisure time to participate in this extracurricular teaching offer. They may be more interested in computer techniques and, therefore, more curious about trying e-learning. Nevertheless, the evaluation of the students' experience is valuable in gathering experience with e-learning in pharmacy. Their feedback will aid in developing other e-learning lectures in the future, which will be part of the regular curriculum and will be mandatory for all students. Modern pedagogic concepts emphasize the value of self-directed learning compared to externally controlled learning [19]. E-learning and computer-based learning represent a first step towards more self-directed learning. A striking difference between e-learning lectures and traditional teaching is the independence from space and time that e-learning provides. This was one of the aspects of e-learning the students rated favorably in the questionnaire.

Pharmacy programs are characterized by a great amount of facts the students must learn. Therefore, self-directed learning has been traditionally rather rare. In educational science, three major learning theories are discussed: (1) behavioristic didactics, (2) cognitive science, which represent externally controlled modes of learning and (3) constructivistic didactics, which tries to foster active student thinking by providing optimal learning environments [20-27]. Although all three didactical concepts are applicable to e-learning, many educational scientists value constructivistic ones as most adequate.

As recently reviewed, e-learning emerged as new field in pharmacy and pharmacology [8]. Our e-learning lecture series on cancer biology and pharmacology was a start-up project to gather experience about the feasibility of e-learning in pharmacy. The students' positive reception will be an encouragement to implement further e-learning offers in pharmacy programs. In addition to developing further e-learning lessons and modules, an electronic resource center related to the topics of the e-learning program is currently in preparation.

\section{Conclusions and Perspectives}

In conclusion, students liked the possibility of self-controlled learning, and e-learning sparked their interest as novel educational method. In addition, they felt quite comfortable listening to the e-learning lectures despite the interdisciplinary mixture of molecular biological, pharmacological and medical 
aspects of cancer biology and pharmacology. This lecture series was the majority of the students' first e-learning experience, and their impressions were generally positive. To the best of our knowledge, this is the only e-learning lecture series on cancer biology and pharmacology in Germany. The students would not only recommend e-learning to other students, but would also like to continue with e-learning themselves. Remarkably, the majority of students would like to have more e-learning offers in their present curricula in the form of mixed traditional learning and e-learning ("blended learning"), although they recognized the importance of face-to-face contact with teachers and students (phases of presence). As a consequence, many students would consider e-learning for further and continuing education after graduation.

Nevertheless, there remains potential for improvement in the future. The interactive space for students is not fully developed in the present form of the e-learning program. Recently we began building interactive teams to write review articles on specific topics related to the e-learning lectures. Here, the students use topics from the e-learning lectures as a starting point and deepen their knowledge by collecting more information from the scientific literature. As an indication of success, it should be noted that several of the students' review articles have been published in scientific journals [28-35]. This kind of teamwork should be strengthened in the future.

\section{Acknowledgement}

I thank Karen Duffy (Cornell University, Ithaca, NY, USA) for reading the manuscript.

\section{References}

1. Lau, F.; Bates, J. A review of e-learning practices for undergraduate medical education. J. Med. Syst. 2004, 28, 71-87.

2. Ruiz, J.G.; Mintzer, M.J.; Leipzig, R.M. The impact of e-learning in medical education. Acad. Med. 2006, 81, 207-212.

3. Beux, P.L.; Fieschi, M. Virtual biomedical universities and e-learning. Int. J. Med. Inform. 2007, 76, 331-335.

4. Cook, D.A.; Levinson, A.J.; Garside, S.; Dupras, D.M.; Erwin, P.J.; Montori, V.M. Internet-based learning in the health professions. J. Am. Med. Assoc. 2008, 300, 1181-1196.

5. Cook, D.A.; Levinson, A.J.; Garside, S. Time and learning efficiency in Internet-based learning: A systematic review and meta-analysis. Adv. Health Sci. Educ. 2010, 15, 755-770.

6. Börchers, M.; Tipold, A.; Pfarrer, Ch.; Fischer, M.R.; Ehlers, J.P. Acceptance of case-based, interactive e-learning in veterinary medicine on the example of the CASUS system. Tierarztl. Prax. Ausg. K. 2010, 38, 379-388.

7. Potomkova, J.; Mihal, V.; Zapletalova, J.; Subova, D. Integration of evidence-based practice in bedside teaching paediatrics supported by e-learning. Biomed. Pap. Med. Fac. Univ. Palacky Olomouc Czech Repub. 2010, 154, 83-87.

8. Efferth, T. E-learning in pharmacology and pharmacy. Educ. Sci. 2011, 1, 4-14.

9. Seppmann, G. Erstellung netzbasierter Vorlesungen mit dem Microsoft Powerpoint Producer; 2002; in German. Available online: http://www.vcrp.de/fileadmin/pdf/videoppt.pdf (accessed on 7 July 2012). 
10. Microsoft Web site. Available online: http://www.microsoft.com/en-us/download/details.aspx?id= 12033 (accessed on 7 July 2012).

11. Presentation Tutorials. 123PPT Website. Available online: http://www.123ppt.com/newsletter/ edition-003/presentation-tutorial.asp (accessed on 7 July 2012).

12. Tran, V.V.; Lichtsteiner, S.; Ernst, B.; Otto, M.; Folkers, G. Towards a virtual education in pharmaceutical sciences: An innovative E-learning approach. Curr. Probl. Dermatol. 2003, $32,43-51$.

13. Franson, K.L.; Dubois, E.A.; de Kam, M.L.; Cohen, A.F. Measuring learning from the TRC pharmacology e-learning program. Br. J. Clin. Pharmacol. 2008, 66, 135-141.

14. O'Shaughnessy, L.; Haq, I.; Maxwell, S.; Llewelyn, M. Teaching of clinical pharmacology and therapeutics in UK medical schools: current status in 2009. Br. J. Clin. Pharmacol. 2010, 70, 143-148.

15. Ryan, G. Online CME: An effective alternative to face-to-face delivery. Med. Teach. 2007, 29, e251-e257.

16. Leikola, S.N.; Tuomainen, L.; Ovaskainen, H.; Peura, S.; Sevón-Vilkman, N.; Tanskanen, P.; Airaksinen, M.S. Continuing education course to attain collaborative comprehensive medicationreview competencies. Am. J. Pharm. Educ. 2009, 73, 108.

17. Moja, L.; Moschetti, I.; Cinquini, M.; Sala, V.; Compagnoni, A.; Duca, P.; Deligant, C.; Manfrini, R.; Clivio, L.; Satolli, R.; et al. Clinical evidence continuous medical education: A randomised educational trial of an open access e-learning program for transferring evidence-based information-ICEKUBE (Italian Clinical Evidence Knowledge Utilization Behaviour Evaluation)—study protocol. Implement. Sci. 2008, 3, 37.

18. Karp, S. E-learning and the enterprise: The Eckerd Corporation brings continuing education to pharmacists nationwide with online learning. Health Manag. Technol. 2001, 22, 32-34.

19. Hutten, H.; Stiegmaier, W.; Rauchegger, G. KISS-A new approach to self-controlled e-learning of selected chapters in medical engineering and other fields at bachelor and master course level. Med. Eng. Phys. 2005, 27, 611-616.

20. Weidenmann, B. Multicodierung und Multimodalität im Lernprozess. In Information und Lernen mit Multimedia; Issing, L.J., Klimsa, P., Eds.; Psychologie Verlags Union: Weinheim, Germany, 1997; pp. 66-84; in German.

21. Mader, G.; Stöckl, W. Virtuelles Lernen: Begriffsbestimmung und Aktuelle Empirische Befunde; Studienverlag: Innsbruck, Austria, 1999; in German.

22. Kerres, M.; Jechle, T. Betreuung des mediengestützten Lernens in telemedialen Lernumgebungen. Unterrichtswissenschaft. Zeitschrift für Lehr-/Lernforschung 2000, 24, 1-13; in German.

23. Schulmeister, R. Virtuelle Universität-Virtuelles Lernen; Oldenbourg Verlag: München, Germany, 2001; in German.

24. Skinner, B.F. Science and Human Behavior; The B.F. Skinner Foundation: Cambridge, MA, USA, 2005. Available online: http://www.bfskinner.org/BFSkinner/PDFBooks_files/Science_and _Human_Behavior.pdf (accessed on 7 July 2012).

25. Anderson, J.R. Kognitive Psychologie: Eine Einführung; Spektrum der Wissenschaft: Heidelberg, Germany, 1988; in German.

26. Gardner, H. Dem Denken auf der Spur: Der Weg der Kognitionswissenschaft; Klett-Cotta: Stuttgart, Germany, 1989; in German. 
27. Lenzen, M. Natürliche und künstliche Intelligenz: Einführung in die Kognitionswissenschaft; Campus: Frankfurt, Germany, 2002; in German.

28. Kober, M.; Pohl, K.; Efferth, T. Molecular mechanisms underlying St. John's wort drug interactions. Curr. Drug Metab. 2008, 9, 1027-1037.

29. Kraft, T.E.; Parisotto, D.; Schempp, C; Efferth, T. Fighting cancer with red wine? Molecular mechanisms of resveratrol. Crit. Rev. Food Sci. Nutr. 2009, 49, 782-799.

30. Bechtle, M.; Chen, S; Efferth, T. Neglected diseases caused by bacterial infections. Curr. Med. Chem. 2010, 17, 42-60.

31. Nussbaum, K.; Honek, J.; Cadmus, C.M.; Efferth, T. Trypanosomatid parasites causing neglected diseases. Curr. Med. Chem. 2010, 17, 1594-1617.

32. Bamberger, D.; Jantzer, N.; Leidner, K.; Arend, J.; Efferth, T. Fighting mycobacterial infections by antibiotics, phytochemicals and vaccines. Microbes Infect. 2011, 13, 613-623.

33. Schleich, K.; Nürnberger, C.; Sobanski, A.; Efferth, T. Vaccination and antiviral treatment of neglected diseases caused by flaviviral infections. Curr. Med. Chem. 2011, 18, 604-614.

34. Müllner, A.; Helfer, A.; Kotlyar, D.; Oswald, J.; Efferth, T. Chemistry and pharmacology of neglected helminthic diseases. Curr. Med. Chem. 2011, 18, 767-789.

35. Wahl, O.; Oswald, M.; Tretzel, L.; Herres, E.; Arend, J.; Efferth, T. Inhibition of tumor angiogenesis by antibodies, synthetic small molecules and natural products. Curr. Med. Chem. 2011, 18, 3136-3155.

(C) 2013 by the authors; licensee MDPI, Basel, Switzerland. This article is an open access article distributed under the terms and conditions of the Creative Commons Attribution license (http://creativecommons.org/licenses/by/3.0/). 